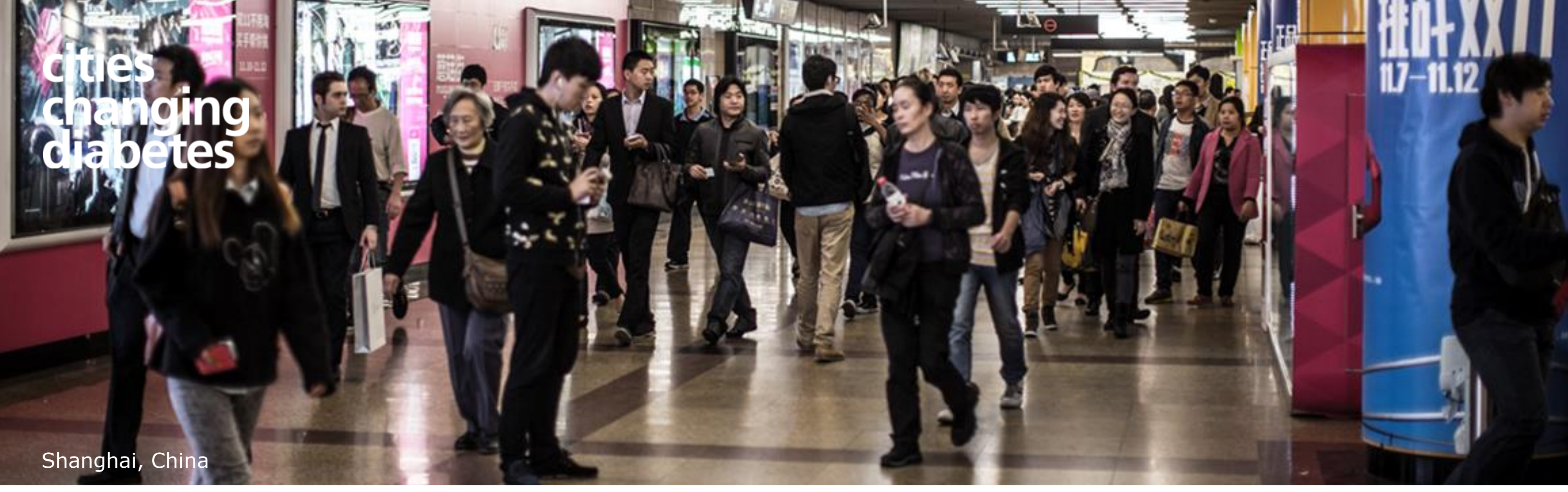

\title{
A NOVEL RESEARCH APPROACH FOR CITIES TO PRIORITISE SOCIAL FACTORS AND CULTURAL DETERMINANTS RELEVANT TO TYPE 2 DIABETES
}

Napier $D^{1}$, Volkmann $A^{1}$, Hesseldal $L^{2}$, Bagger $M^{2}$

\section{INTRODUCTION}

Social factors and cultural determinants constitute both barriers and opportunities for successful prevention, care and management of type 2 diabetes (T2D). Understanding priorities, attitudes, and shared viewpoints among people with T2D in light of social and cultural factors allows for more precise tailoring of health interventions. To this end, we present a novel research tool, the Diabetes QAssessment (D-QA), also known as the Urban Diabetes Risk Assessment. The D-QA is based on Q-Methodology ${ }^{1}$. The tool, developed for the Cities Changing Diabetes (CCD) programme, builds on eight locally distinct and globally shared social factors and cultural determinants relevant to T2D emerging from more than 700 individual interviews conducted in five cities joining $\mathrm{CCD}^{3}$.

\section{RESEARCH AIM}

- To study presence and impact of local social factors and cultural determinants of T2D across population groups.

- To enable cities to prioritise addressing specific local social factors and cultural determinants relevant to T2D.

- To inform interventions and improve both prevention, care and management of T2D.

\section{METHOD}

- Target population is defined (e.g. specific city area). 50-60 participants each carry out a computer-based sorting of 64 statements (Q-sort) reflecting the eight social factors and cultural determinants into a forced distribution matrix to ensure participants relate statements to each other and think carefully about which statements take priority over others (Figure 1).

- Correlation analysis identify similarities between individual Q-sorts and factor analysis group participants with similar viewpoints.

- Focus group interviews with selected participants from each group deepen and validate findings.

\section{FIGURE 1. FORCED DISTRIBUTION MATRIX}

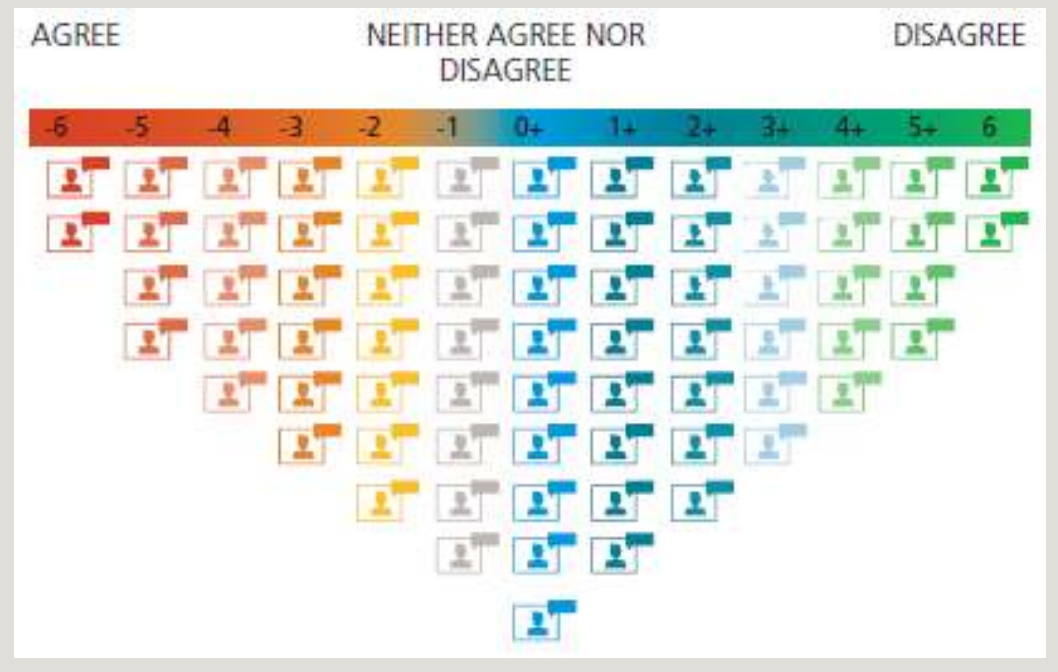

\section{RESULTS}

The results will contribute to answer the following research questions:

- What characterises the participants in terms of their needs and capabilities regarding diabetes, health and wellbeing?

What are the social factors and cultural determinants that matter most to people with T2D among the target population?

How do those factors and determinants create barriers to and opportunities for successful diabetes prevention, care and management, and improved wellbeing?

\section{CONCLUSION}

Through a deeper understanding of how the social

factors and cultural determinants of T2D play out in a given city, diabetes prevention, care and management can be improved upon and tailored to specific target groups.

REFERENCES: 1.

\section{URBAN DIABETES}

- $54 \%$ of world's population live in urban areas - this is set to increase to $66 \%$ by $2050^{3}$.

- 415 million people have diabetes worldwide - this is set to increase to 642 million by $2040^{4}$.

- $65 \%$ of people with diabetes live in urban areas - this is set to increase to $74 \%$ by $2040^{4}$.

\section{CITIES CHANGING DIABETES}

- AIM: to map the diabetes challenge, share the knowledge, and drive concrete actions in cities.

- SET UP: global cross-disciplinary partnership - Novo Nordisk A/S, Steno Diabetes Center Copenhagen, and University College London.

\section{CURRENT CITIES IN CITIES CHANGING DIABETES}

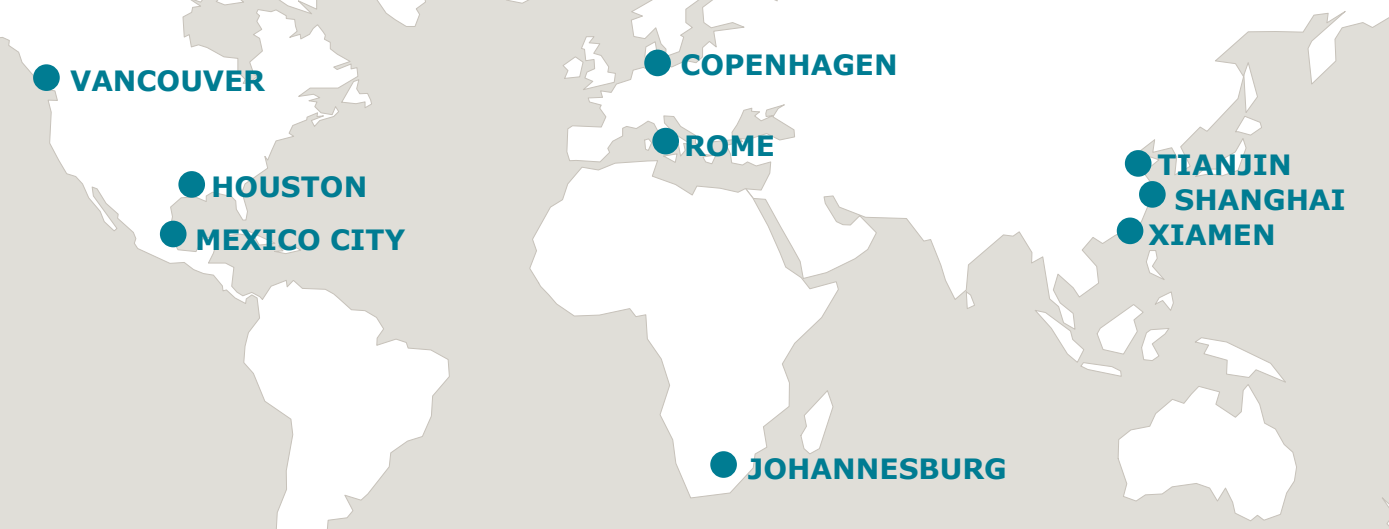

